\title{
Current perspectives on the role of interleukin-1 signalling in the pathogenesis of asthma and COPD
}

\author{
Emmanuel T. Osei ${ }^{1,2}$, Corry-Anke Brandsma ${ }^{3,4}$, Wim Timens $^{3,4}$, \\ Irene H. Heijink ${ }^{3,4,5}$ and Tillie-Louise Hackett ${ }^{1,2}$
}

Affiliations: ${ }^{1}$ Centre for Heart Lung Innovation, St Paul's Hospital, Vancouver, BC, Canada. ${ }^{2}$ Dept of Anesthesiology, Pharmacology and Therapeutics, University of British Columbia, Vancouver, BC, Canada. ${ }^{3}$ Dept of Pathology and Medical Biology, University Medical Center Groningen, University of Groningen, Groningen, The Netherlands. ${ }^{4}$ Groningen Research Institute of Asthma and COPD (GRIAC), University Medical Center Groningen, University of Groningen, Groningen, The Netherlands. ${ }^{5}$ Dept of Pulmonology, University Medical Center Groningen, University of Groningen, Groningen, The Netherlands.

Correspondence: Emmanuel T. Osei, Centre for Heart Lung Innovation, University of British Columbia and St Paul's Hospital, Room 166, 1081 Burrard Street, Vancouver, BC V6Z 1Y6, Canada.

E-mail: emmanuel.oseidahli.ubc.ca

@ERSpublications

Interleukin-1 signalling plays a major contributory role in the pathogenesis of asthma and COPD http://bit.ly/2qHSvEM

Cite this article as: Osei ET, Brandsma C-A, Timens W, et al. Current perspectives on the role of interleukin-1 signalling in the pathogenesis of asthma and COPD. Eur Respir J 2020; 55: 1900563 [https:// doi.org/10.1183/13993003.00563-2019].

ABSTRACT Asthma and chronic obstructive pulmonary disease (COPD) cause significant morbidity and mortality worldwide. In the context of disease pathogenesis, both asthma and COPD involve chronic inflammation of the lung and are characterised by the abnormal release of inflammatory cytokines, dysregulated immune cell activity and remodelling of the airways. To date, current treatments still only manage symptoms and do not reverse the primary disease processes. In recent work, interleukin (IL)- $1 \alpha$ and IL-1 $\beta$ have been suggested to play important roles in both asthma and COPD. In this review, we summarise overwhelming pre-clinical evidence for dysregulated signalling of IL- $1 \alpha$ and IL- $1 \beta$ contributing to disease pathogenesis and discuss the paradox of IL-1 therapeutic studies in asthma and COPD. This is particularly important given recent completed and ongoing clinical trials with IL- 1 biologics that have had varying degrees of failure and success as therapeutics for disease modification in asthma and COPD. 


\section{Introduction}

The morbidity and mortality associated with asthma and chronic obstructive pulmonary disease (COPD) results in a substantial economic and social burden around the world, which is still rising [1-3]. More effective therapeutics are clearly needed to not only manage chronic inflammatory symptoms in asthma and COPD, but also resolve the underlying disease pathologies. While there is overwhelming pre-clinical evidence of the involvement of various immune mediators in the pathogenesis of asthma and COPD, these have not yet been successfully translated into therapies. One such important mediator is the major master regulatory cytokine, interleukin (IL)-1.

While asthma and COPD are both characterised by chronic airway inflammation and airway remodelling [4], the master cytokines involved are substantially different for each disease $[5,6]$. This notwithstanding, IL-1 has been shown to be involved in many aspects of inflammation in asthma and COPD [7-13]. In asthmatic subjects, in response to triggers such as allergens or exercise, IL-1 is released as an immune mediator or damage-associated molecular pattern (DAMP) together with other master cytokines, i.e. thymic stromal lymphopoietin (TSLP) and granulocyte monocyte-colony stimulating factor (GM-CSF) within the airways, resulting in eosinophilia, IgE switching [14] and type 2 helper T-cell (Th2) inflammation (IL-4, IL-9 and IL-13) [14-17]. In COPD, damage from inhaled noxious particles, such as cigarette smoke [18], also causes IL-1 release, along with other master cytokines, i.e. tumour necrosis factor (TNF)- $\alpha$, IL-6 and IL-8/CXCL8, to cause neutrophilia, macrophage activation, and type 1 helper T-cell (Th1) and type 1 cytotoxic T-cell (Tc1) responses [19-25]. In addition, IL-1 signalling is directly involved in various aspects of airway remodelling. These include smooth muscle activation and airway hyperresponsiveness (AHR) in asthma [26, 27] as well as chronic mucus hypersecretion [28, 29] and abnormal extracellular matrix (ECM) protein production in both diseases [9, 30, 31].

The existence of a common mediator for the pathogenesis of asthma and COPD such as IL-1 might explain why epidemiological studies show that both diseases may coexist or evolve into each other, termed asthma-COPD overlap syndrome (ACOS) [32]. For example, eosinophilic airway inflammation is found in some COPD patients and associates with greater steroid-mediated reversibility of airflow obstruction [4]. On the other hand, neutrophilic inflammation in severe asthmatic subjects is associated with steroid resistance [32]. Interestingly, IL-1 signalling has been shown to be associated with both eosinophilic and neutrophilic inflammatory profiles in both diseases $[12,33]$. These inflammatory profiles form the basis of different disease subphenotypes in addition to factors such as aetiology (allergic/nonallergic), syndrome type (e.g. ACOS) and disease severity for asthma, and for COPD, different overlaps of disease presentations, including small airway disease [34], emphysema [35] and the COPD-asthma phenotype (ACOS) [36]. Of note, the expression levels of IL-1 receptor (IL-1R) 1 and other signalling molecules of the IL-1 pathway in sputum were found to be important predictors of frequent exacerbations in asthma and COPD patients [37].

The heterogeneity in disease subphenotypes presents a substantial hurdle for research into curative therapies and underlies the importance for understanding the roles of a common master regulator such as IL-1. Although this is known and well understood in the field, there are limited data on the levels of IL-1 in patients stratified into various specific disease subphenotypes of asthma and COPD.

There are different commercially available drugs to regulate IL-1 signalling, including IL-1R antagonists, humanised monoclonal antibodies and soluble decoy fusion proteins that block the IL-1 pathway in disease $[38,39]$. However, the few clinical trials that have assessed the use of IL-1 therapeutics in asthma and COPD have largely failed to yield positive results. This raises important questions about the paradox of translating important pre-clinical research in diseases such as asthma and COPD into successful therapeutics. Hence, this review will specifically examine and summarise current knowledge on the biology and contribution of IL-1 to the pathogenesis of asthma and COPD. Furthermore, we assess the paradox of the failed clinical trials, and evaluate the implications and usefulness of therapeutically targeting this cytokine.

\section{Regulation of IL-1 signalling within the lung}

In the lung, IL-1 is primarily produced by the airway epithelium and macrophages [40], and its expression can be induced to varying degrees by lung fibroblasts, neutrophils and T-cells [9, 39, 41]. IL-1 denotes two variant cytokines, IL- $1 \alpha$ and IL-1 $\beta$, with closely related polypeptides, which are part of a larger family of seven agonists (including IL-18, IL-33, IL-36 $\alpha$, IL-36 $\beta$ and IL-36 $\gamma$ ). IL- $1 \alpha$ and IL-1 $\beta$ are encoded by different genes and are synthesised as $31 \mathrm{kDa}$ precursor molecules with missing leader sequences. Pro-IL- $1 \alpha$ is biologically active, but can undergo cleavage by calpain, a cysteine protease activated by calcium, to generate an additional biologically active $18 \mathrm{kDa}$ mature form. Pro-IL-1 $\beta$ is not biologically active and requires activation through cleavage by caspase- 1 (IL-1 $\beta$ converting enzyme), which occurs after processing by the nucleotide oligomerisation binding domain-like receptor protein (NLRP) 3 
inflammasome complex to generate a biologically active $17 \mathrm{kDa}$ mature IL-1 $\beta$ [42]. The inflammasome is activated when pathogen-associated molecular patterns (PAMPs) or DAMPs (e.g. ATP) released upon cell damage or death activate pattern recognition receptors such as Toll-like receptor (TLR) 4 and the $\mathrm{P}_{2} \mathrm{X}_{7}$ purinergic receptor [43]. In various animal studies it has been shown that inflammasome activation is directly involved in inflammatory, fibrotic or emphysematous responses to inhalation-related insults within the lung, including allergens (in asthma) and noxious agents, e.g. ozone, alum and bleomycin modelling fibrosis and/or emphysema [44-46].

Despite differences in activation, IL- $1 \alpha$ and IL- $1 \beta$ bind individually to the same IL-1R1 [40]. The binding of IL- $1 \alpha / \beta$ to IL-1R1 forms the IL-1R1 complex, activating signalling through the classical Toll interleukin receptor (TIR)/myeloid differentiation primary response gene 88 (MyD88) pathway (figure 1). This signalling pathway significantly overlaps with the TLR pathway and is shared between most members of the IL-1 family. This pathway specifically leads to the nuclear translocation of transcription factors, such as p38 mitogen-associated protein kinase, c-Jun N-terminal kinase, activator protein-1 and NF- $\mathrm{B}$, which promote the expression of a wide variety of inflammatory cytokines and growth factors (figure 1) [47-50].

The signalling of IL- $1 \alpha / \beta$ is regulated at various levels by anti-inflammatory family members and receptors (figure 2). Compared with IL-1R1, the decoy IL-1R2 is a biologically inert receptor that can also bind IL- $1 \alpha / \beta$ and prevent signalling $[40,51]$. The IL-1R antagonist (IL-1RA) is an anti-inflammatory family member that competes for the IL-1R1 binding site and regulates the function of IL-1 $\alpha / \beta$ [42]. In line with this, various studies have shown a lower expression of IL-1R2 and IL-1RA in asthma and COPD causing increased IL-1 activity due to the lack of adequate anti-inflammatory regulation [11, 52-54]. In addition, the activity of IL-1 can also be regulated by epigenetic factors. Increased methylation of the IL1R2 gene locus is associated with a lower expression of the anti-inflammatory IL-1R2, which may add to increased

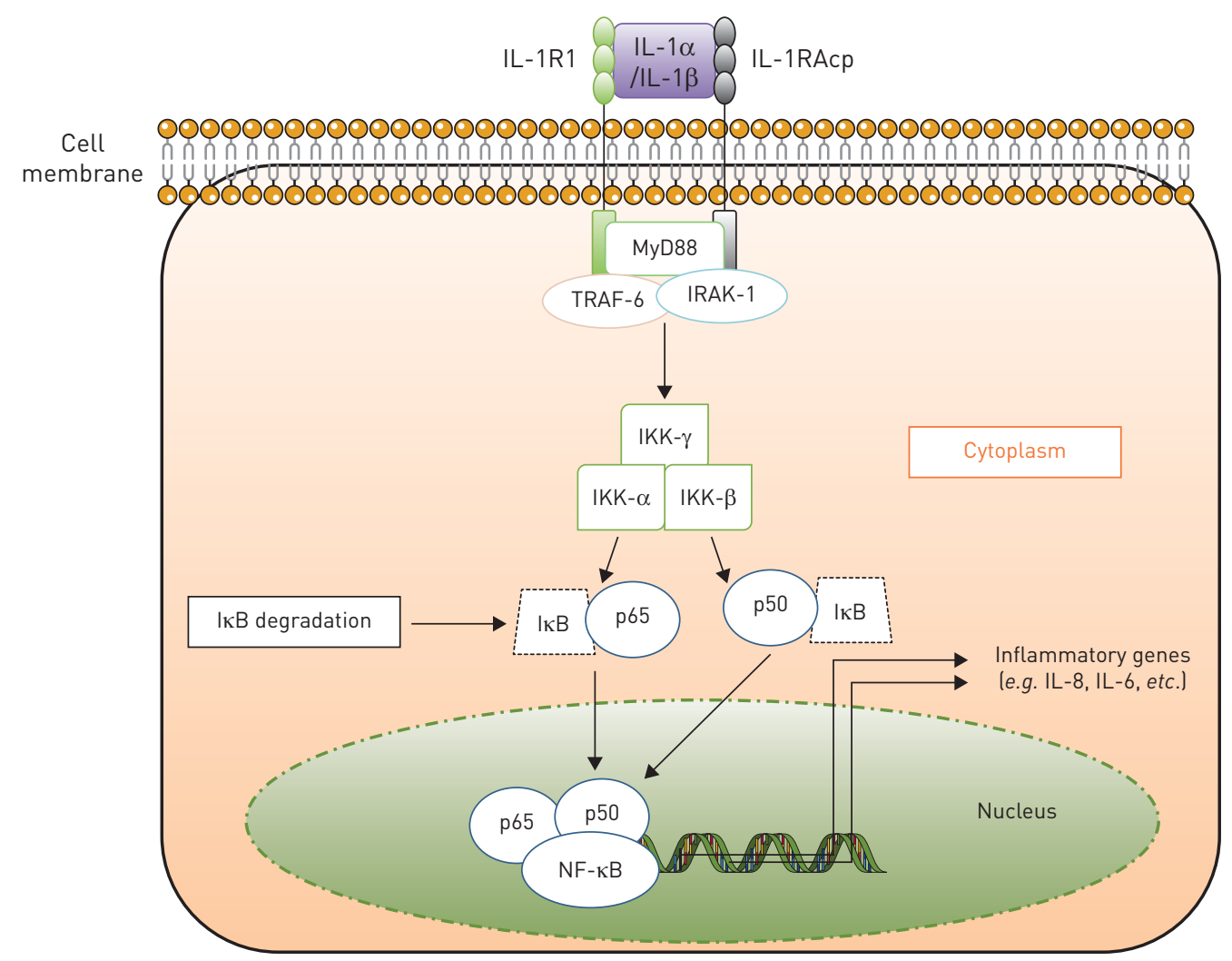

FIGURE 1 Classical interleukin (IL)-1 signalling. IL-1R: IL-1 receptor; IL-1RAcp: IL-1R accessory protein; MyD88: myeloid differentiation primary response gene 88; IRAK: IL-1R-associated kinase; TRAF: tumour necrosis factor receptor-associated factor; IKK: IKB kinase. IL-1 $\alpha$ and IL-1 $\beta$ both share the same receptor IL-R1. The binding of IL-1 $\alpha$ or IL-1 $\beta$ individually to IL-1R1 causes the formation of a receptor complex with IL-1RAcp. The formation of this receptor complex leads to the recruitment of the adaptor MyD88, which leads to the further recruitment of IRAK- 1 and TRAF- 6 . This leads to the phosphorylation of IKK- $\alpha$, IKK- $\beta$ and IKK- $\gamma$ that leads to the degradation of $\mid \kappa B$, the translocation of $N F-\kappa B$ subunits $p 65$ and $p 50$ into the nucleus, and the transcription of various inflammatory genes. Other nuclear transcription factors that may be activated include activator protein-1, c-June N-terminal kinase and p38 mitogen-associated protein kinase. 


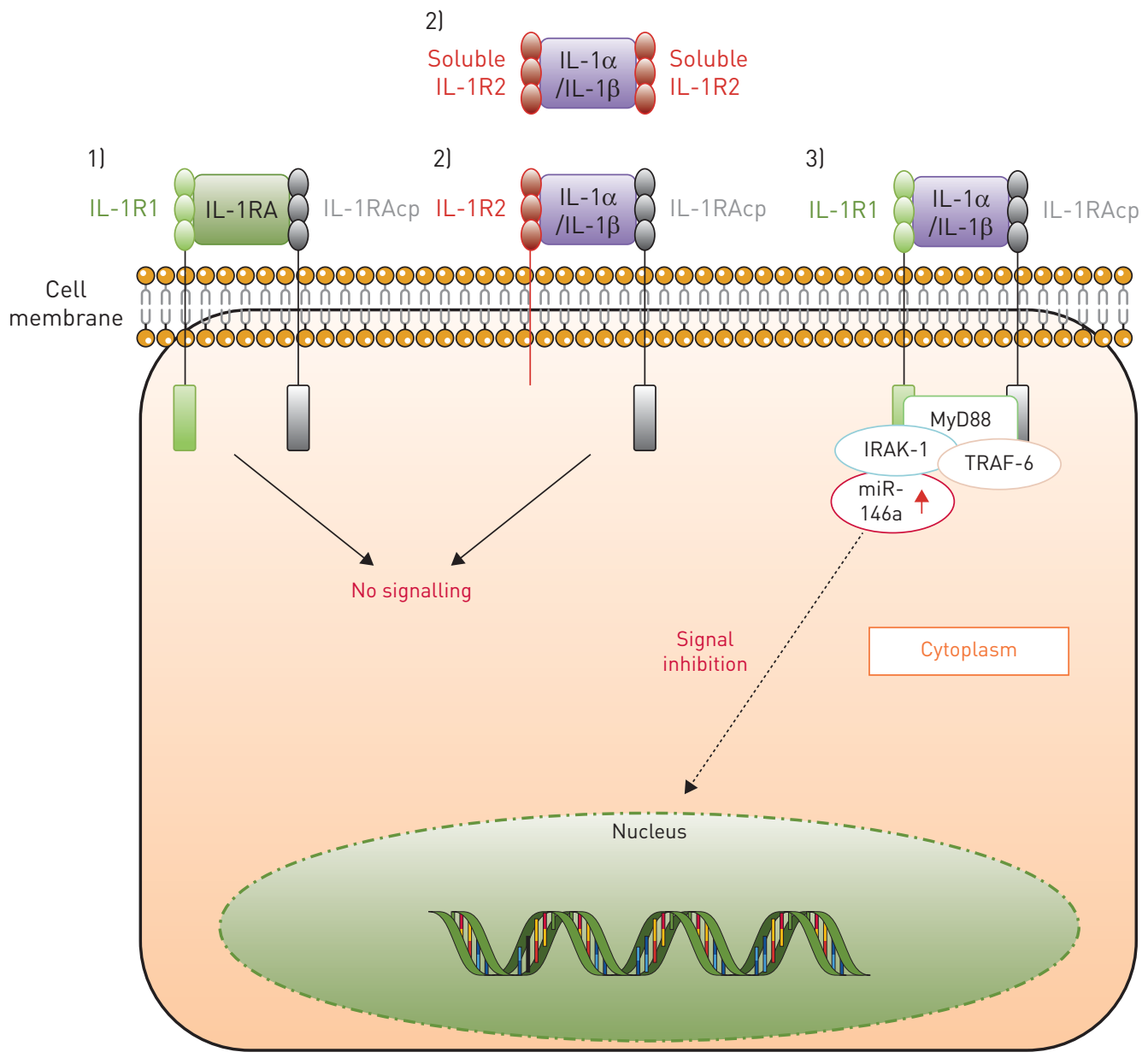

FIGURE 2 Regulation of interleukin (IL)-1 signalling. IL-1R: IL-1 receptor; IL-1RA: IL-1R antagonist; IL-1RAcp: IL-1R accessory protein; MyD88: myeloid differentiation primary response gene 88; IRAK: IL-1R-associated kinase; TRAF: tumour necrosis factor receptor-associated factor. The regulation of IL-1 signalling includes anti-inflammatory family members and epigenetic mechanisms such as microRNA regulation. 1) IL-1RA competes with IL-1 $\alpha$ and IL-1 $\beta$, and binds to IL-1R1 to prevent IL-1 signalling. 2) IL-1R2 is a decoy receptor that can form either a homodimer resulting in a soluble form which can bind extracellular IL-1 or forms a heterodimer with IL-1RAcp which is found at the membrane surface but lacks a cytoplasmic domain that can initiate IL-1 signalling. 3) IL-1 signalling can also be controlled by epigenetic mechanisms such as the increased expression of miR-146a, which binds and downregulates IRAK-1 and TRAF-6 to prevent biological signalling.

IL-1 activity in asthmatic subjects [52]. Short interfering RNAs such as microRNAs also regulate IL-1 signalling. In particular, miR-149 and miR-146a do not only have altered expression in COPD, but also influence IL-1 signalling in COPD $[55,56]$. As an example, we have shown that miR-146a-5p binds to and downregulates the expression of IL-1 receptor-associated kinase (IRAK)-1, a mediator in the IL-1 pathway to inhibit lung fibroblast responses to IL-1 $\alpha$ [57]. Hence, a balance between IL-1 signalling and its regulation in the lung is not only essential for normal immune defence but is also important in the pathogenesis of diseases such as asthma and COPD.

\section{IL-1 $\alpha$ and IL-1 $\beta$ : master regulators in the lung immune defence}

In the lung, IL- $1 \alpha$ and IL- $1 \beta$ are essential for the immune defence against various inhaled noxious agents, including nanoparticles (silica and titanium dioxide) [58, 59], ozone [46, 60], particulate matter [61], cigarette smoke [62] and pathogens such as respiratory viruses [63]. In the lung, IL-1 is released early to drive the inflammatory response as evidenced in a mouse model of acute silica exposure. Here, IL- $1 \alpha$ was released in the first hours after challenge and peaked after $6-12 \mathrm{~h}$, to stimulate the release of inflammatory mediators including IL-1 $\beta, 24 \mathrm{~h}$ later [58].

The airway epithelium is the structural barrier which forms the first part of innate immunity in the lung, and constitutively produces and stores IL-1 $\alpha$ primarily as a membrane-associated form [42, 64]. 
IL- $1 \alpha$ can also be rapidly shuttled into the nucleus to initiate transcription [40]. In apoptotic conditions, IL- $1 \alpha$ translocates into the nucleus and remains bound to chromatin. However, in necrotic conditions, such as during cellular damage caused by inhaled noxious particles, IL- $1 \alpha$ is released and acts as an "alarmin" or DAMP [58]. Thus, upon exposure of the airway epithelium to inhaled noxious particles (smoke) or allergens, IL- $1 \alpha$ and IL-1 $\beta$ are among the initial immune mediators released [58]. This induces inflammation by activating the synthesis and release of a wide variety of chemokines and growth factors $[49,65]$. In addition, recruited alveolar macrophages are also responsible for the release of high concentrations of IL- $1 \alpha / \beta$ [8]. The receptors for IL- 1 are found on most immune and structural cells of the lung, and IL-1 acts in concert with other innate cytokines (e.g. TNF- $\alpha$ ) to activate master transcription factors of inflammation such as $\mathrm{NF}-\kappa \mathrm{B}$ and activator protein-1 to activate innate and adaptive immunity [39].

IL- $1 \alpha / \beta$ signalling can also contribute to repair, remodelling and fibrosis of the lung [39]. Using a co-culture model, we have shown that airway epithelial-derived IL- $1 \alpha$ regulates the production of inflammatory cytokines and ECM proteins by lung fibroblasts [62]. Specifically, airway epithelial-derived IL-1 $\alpha$ stimulated inflammatory cytokine release (CXCL8 and IL-6) and suppressed the expression of ECM proteins (collagen I $\alpha 1$ and fibronectin) by lung fibroblasts. IL-1 $\alpha$ also suppressed the production of the classical pro-fibrotic cytokine, transforming growth factor (TGF)- $\beta$, in lung fibroblasts [62]. Other studies have revealed a possible counteractive interaction between IL-1 and TGF- $\beta$, which may play a role in fibrosis and airway remodelling. Specifically, TGF- $\beta$ supports the survival of pro-fibrotic myofibroblasts by inhibiting IL-1 $\beta$-induced apoptosis [66], while IL- $1 \beta$ inhibits TGF- $\beta 1$-dependent fibroblast-myofibroblast transformation [67]. This interaction points to a balance between IL-1 and TGF- $\beta$ signalling in the lung during repair processes that may be disrupted due to abnormal remodelling in asthma and COPD. Cross-talk between the endoderm- and mesoderm-derived cells may provide a mechanism whereby the mesenchymal lung tissue is primed to respond to inflammation and prevented from uncontrolled ECM production. This is supported by data demonstrating that IL-1 $\beta$ at low and high concentrations is a major inducer of cyclooxygenase- 2 and prostaglandin $E_{2}$ in human lung fibroblasts, which inhibit increased fibroblast proliferation. However, at moderate concentrations, IL-1 $\beta$ induces accelerated fibroblast proliferation, demonstrating a concentration-dependent biphasic effect of IL-1 $\beta$-induced lung fibroblast proliferation [68]. This shows that both the temporal release and concentration of IL-1 may be essential for specific IL-1-driven responses within the lung micro-environment. However, in lung diseases such as asthma and COPD, the global activity and release of IL- 1 is increased, and this could serve as a target for IL-1-specific therapeutic studies.

\section{IL-1 in the pathogenesis of asthma}

In asthma, IL-1 plays an important role in the pathogenesis of different molecular phenotypes of the disease. IL- $1 \alpha$ and IL- $1 \beta$ are known to contribute to Th2 inflammation in asthma through the activation and recruitment of eosinophils, mast cells, dendritic cells and other inflammatory cells like neutrophils in neutrophilic asthma $[12,69]$. IL- $1 \alpha / \beta$ concentrations are increased in sputum and bronchial lavage fluid (BALF) from symptomatic asthma patients compared with asymptomatic asthmatic subjects [70-72]. In a study by Busse et al. [73], an increased IL-1 $\beta$ concentration together with IL- 6 and CCL20 was found in the sputum of older patients with more severe asthma and was associated with increased neutrophil counts compared with younger patients with less severe asthma. LiU et al. [74] also found increased IL-1 $\alpha$ concentrations in the BALF of asthma patients who had a Th2/Th17 low phenotype together with increased neutrophilia. In addition, IL-1 $\beta$ concentrations were increased in both Th2/Th17-predominant patients who had increased eosinophilia and Th2/Th17 low phenotype asthma patients [74]. This increased production originates from the airway epithelium and macrophages as demonstrated by SousA et al. [11], who showed increased protein expression of IL-1 $\beta$ and IL-1RA in these cells from atopic asthmatic patients compared with normal control individuals. These findings of elevated IL-1 levels and the discovery that IL-1R1-IL-1 signalling contributes to airway inflammation and remodelling have raised interest in the potential for targeting IL-1R1 therapeutically in asthma [69].

Several in vitro and in vivo studies have assessed the link between allergen triggers and increased levels of IL-1 in asthma. When stimulated with house dust mite (HDM), an asthma allergen, airway epithelial cells released IL- $1 \alpha$ and IL- $1 \beta$ to stimulate IL-6, GM-CSF and IL-33, both in an autocrine manner and from immune cells such as monocytes $[12,75,76]$. IL- $1 \beta$-dependent control of hypoxia inducible factor- $1 \alpha$ is involved in chronic mucus hypersecretion in asthma through the overexpression of MUC5AC, an important mucin in bronchial epithelial cells [28]. Using bronchial air-liquid interface cultures, it was also determined that autocrine TLR4-dependent IL-1 $\alpha$ production stimulates GM-CSF and IL-33 to recruit dendritic cells involved in asthmatic Th2 inflammation and allergic sensitisation [12]. In in vivo studies, Willart et al. [12] exposed IL-1R knock-out mice to HDM and found that they were protected against Th2 inflammation compared with air-exposed mice. In an ovalbumin (OVA) sensitisation mouse model, 
deletion of IL- $1 \alpha / \beta$ expression strongly attenuated AHR with decreased T-cell proliferation and inflammation, and loss of B-cell IgG1 and IgE production [77]. Conversely, knocking out the anti-inflammatory IL-1RA caused an increased AHR response and T-cell cytokine production [77]. In addition, IL-1R1 knock-out and administering IL-1 $\alpha / \beta$ neutralising antibodies in a toluene diisocyanate-induced asthma mouse model significantly reduced AHR and abrogated various inflammatory features of asthma. These included decreased IgG1, airway epithelium hyperplasia, lymphocyte influx and eosinophilia, along with decreased IL-4 and vascular adhesion molecule-1 production [78].

To further dissect the role of IL-1 in specific phenotypes of asthma, ScHmitz et al. [13] investigated IL-1R1 knock-out in a mild in vivo asthma model with low-dose OVA challenges with no adjuvant. While IL-1R1 signalling was dispensable in more severe models, in this mild asthma model it led to a robust reduction in goblet cell hyperplasia, Th2 cell proliferation and dysregulated IgE responses [13]. Apart from the regulation of Th2 inflammation, IL-1 also activates and causes the proliferation of group 2 innate lymphoid cells (ILC2s) that promote the release of Th2 cytokines independent of Th2 cells in allergic asthma $[79,80]$. Here, IL- $1 \beta$ in the presence of IL-12 was shown to potentiate ILC2 switching in an in vivo mouse model [80]. IL-1 $\beta$ signalling is also crucial for glycolysis-mediated inflammatory responses in an allergic mouse model. IL- $1 \alpha / \beta$ administration led to increased glycolytic flux and an increase in genes of glycolytic mediators such as lactate dehydrogenase A [81]. In addition, IL-1-induced TSLP and GM-CSF release in airway epithelium were mediated by increased glycolysis [81]. This suggests a potential link between energy metabolism and IL-1 pro-inflammatory responses in the airways.

Various in vivo models have also demonstrated a critical role of the NLRP3 inflammasome complex in asthma activated in response to inhaled allergens [82]. In allergic HDM and OVA models without an alum adjuvant, NLRP3 inflammasome activation and subsequent IL-1 $\beta$ release is essential for allergic airway inflammation $[83,84]$. In these models, deletion of NLRP3 caused an abrogation of eosinophil recruitment and Th2 inflammation [83, 84]. Mechanistically, inflammasome activation has been attributed to the activity of DAMPs (e.g. ATP and uric acid) released after allergen exposure in the airways [85]. More recently, a nontypeable Haemophilus influenzae and Chlamydia muridarum infection was used to demonstrate a crucial role for the NLRP3 inflammasome and IL-1 $\beta$ signalling in an OVA mouse model of steroid-resistant asthma [86]. Specifically, inhibition of IL-1 $\beta$ and the NLRP3 inflammasome led to suppression of important characteristics of steroid-resistant asthma, including neutrophil influx and nonresponsive AHR [86]. Translating these findings to the clinical setting, inflammasome activation and release of active IL-1 $\beta$ in patients with neutrophilic asthma was strongly linked with inhaled corticosteroid insensitivity [86-88]. Furthermore, the expression of IL-1R1 and its accessory protein (IL-1RAcp) strongly correlates with neutrophil counts in the sputum of asthmatic subjects compared with controls [89]. There is also a strong correlation between increased IL-1R1 (and IL-1RAcp) expression and a reduced ratio of forced expiratory volume in $1 \mathrm{~s}\left(\mathrm{FEV}_{1}\right)$ to forced vital capacity in asthma. This indicates that IL-1-induced neutrophilia may have a prominent contributory role in airflow obstruction in asthma [89].

IL-1 signalling also contributes to subepithelial airway remodelling, as it has been implicated in airway smooth muscle (ASM) sensitisation in asthma [26]. In addition, IL-1RA and the soluble decoy IL-1R2 abrogate both IL-5- and IgE-dependent ASM contraction [26]. A combined stimulation of IgE, IL-5 and IL-1 $\beta$ causes an enhanced production of IL-1 in human ASM cells [26]. This can synergistically act with TNF- $\alpha$ in an autocrine manner to stimulate production of IL- 6 and GM-CSF from ASM cells [27]. We have also shown in preliminary work using a three-dimensional collagen I gel assay that both IL-1 $\alpha$ and IL-1 $\beta$ inhibit the ability of lung fibroblasts to repair and remodel fibrillar collagen I [90]. Such a response has potential implications for the effect of an increased production of IL- $1 \alpha / \beta$ on collagen repair in the airways of asthmatic patients [90]. However, compared with the body of work supporting the role of IL-1 in allergic airway inflammation, more studies are needed to determine the specific mechanisms by which IL-1 contributes to airway remodelling in asthma.

A decreased activity of anti-inflammatory IL-1 regulators due to an underlying genetic predisposition has been shown to cause increased IL-1 activity in asthma patients [52]. The presence of an A2 allele in the IL1RN gene (which encodes for IL-1RA) was associated with nonatopic asthma in a Japanese population and correlated with a lower serum concentration of IL-1RA [53]. Furthermore, a gain-of-function single nucleotide polymorphism (SNP) in the IL1A gene was associated with reduced lung capacity in asthmatic children from Brazil [91]. GAGNÉ-OuelLET et al. [52] also showed an epigenetic regulatory component may be involved in IL-1 dysregulation in asthma. Here, increased DNA methylation of the IL1R2 promoter negatively correlated with IL-1R2 mRNA expression in atopic and asthmatic subjects compared with controls [52]. This led to lower expression of the anti-inflammatory decoy IL-1R2 receptor in asthmatic subjects and increased IL-1 activity [52]. 
The studies reviewed in this section point to not only an increased production and activity of IL-1 in asthmatic patients and a functional role in animal models, but also a genetic component that may predispose asthmatic subjects to downregulate anti-inflammatory regulators of increased IL-1 activity. This could inform pharmacogenomic studies of IL-1 therapeutics in asthma.

\section{IL-1 in the pathogenesis of COPD}

Increased expression and release of IL-1 plays a role in different phenotypes that make up COPD, including small airway disease and emphysematous destruction. Specifically, mRNA and protein levels of IL- $1 \alpha$ and IL- $1 \beta$ are increased in the serum, lung biopsies, sputum and BALF of COPD patients compared with healthy controls irrespective of smoking status $[7,8,10,92]$. The increased level of IL-1 $\beta$ in particular has been associated with increased NLRP3 inflammasome activation in COPD patients [93]. The levels of IL-1 may also help to differentiate COPD phenotypes. Increased levels of IL-1 $\beta$ have been observed in the serum of patients during acute exacerbations of COPD (AECOPD) compared with stable COPD patients and healthy smoking and nonsmoking controls [33]. This increased release of IL-1 $\beta$ in AECOPD is positively correlated with the number of pack-years, percentage neutrophil counts and C-reactive protein (CRP) in the serum, while negatively correlating with $\mathrm{FEV}_{1}$ [33]. In addition, mRNA levels of the NLRP3 inflammasome were found to be increased in peripheral blood mononuclear cells and bronchial biopsies from AECOPD patients compared with control smokers [94].

The plasma levels of IL-1 $\beta$ negatively correlate with $\mathrm{FEV}_{1}$ and pack-years in COPD patients [54]. The proposed source of these elevated levels of IL-1 $\beta$ are the airway epithelium and macrophages, which highly express IL-1 $\beta$ in the lungs of COPD patients [54]. IL-1 $\beta$ also acts on these same cells, expressing IL-1R1 in an autocrine manner to stimulate CXCL8 and GM-CSF release [8]. These then recruit and maintain neutrophils, one of the major cell types involved in airway inflammation in COPD [95]. There is also a corresponding dampening of the inhibitory activity of IL-1, as concentrations of IL-1RA and IL-1R2 are decreased in sputum and plasma of COPD patients compared with nonsmoking controls [54]. Thus, IL-1 release not only correlates with smoking status, but also with lung function decline, indicating its important role in COPD pathogenesis.

To understand the mechanisms underlying the increase of IL-1 in COPD, in vitro and in vivo models have been used. Increased expression and release of IL-1 in vitro from the airway epithelium and macrophages have been shown after exposure to cigarette smoke, other noxious particles such as particulate matter and various infectious agents, e.g. H1N1 influenza, lipopolysaccharide and polyinosinic:polycytidylic acid (poly (I:C)) $[29,61,62,96,97]$. Furthermore, various in vivo studies using cigarette smoke exposure in mice have found increased release of IL- $1 \alpha$ and IL-1 $\beta$. Cigarette smoke exposure causes increased concentrations of IL- $1 \alpha$ and pro-IL-1 $\beta$ in the bronchoalveolar space and lung parenchyma through a TLR4/MyD88-dependent mechanism [98]. IL-1R1 knock-out and IL-1 $\alpha / \beta$ neutralisation (with an antibody) in mice led to protection against cigarette smoke-induced inflammation in the lung due to decreased inflammatory cytokines in lung homogenates compared with wild-type mice [7]. Cigarette smoke-induced lung inflammation was shown to be NLRP3 inflammasome and caspase-1 independent, indicating a dependence on IL- $1 \alpha$, but not IL-1 $\beta$ signalling [7]. In another study, caspase- 1 knock-out and administration of neutralising antibodies in mice showed cigarette smoke-induced lung inflammation and neutrophil influx is dependent on IL- $1 \alpha$, but not IL-1 $\beta$ [8]. In this and another study, IL-1 signalling has also been linked to viral-induced inflammation as IL-1 inhibition attenuated H1N1 influenza-induced inflammation after cigarette smoke exposure $[8,29]$. This leads to a significant reduction in inflammatory mediators and MUC5AC expression with decreased numbers of neutrophils and macrophages [29]. In support of these findings, NiкоTA et al. [99] showed that exaggerated IL-1 $\alpha$ production is crucial for cigarette smoke-induced neutrophilia through a CXCR2-dependent mechanism upon infecting mice with a nontypeable $H$. influenzae strain. Compared with the selective role of IL- $1 \alpha$ over IL- $1 \beta$ reported in the aforementioned models, other studies have shown an increased activation of the NLRP3 inflammasome and IL-1 $\beta$ release [93]. Noxious agents such as particles with a $50 \%$ cut-off aerodynamic diameter of $10 \mu \mathrm{m}\left(\mathrm{PM}_{10}\right)$ and cigarette smoke exposure in the airway epithelium in vitro and in mice activate IL-1R1 and the NLRP3 inflammasome, leading to the release of IL-1 $\beta$ and other mediators such as GM-CSF and CCL20, which cause neutrophilia and activation of dendritic cells in COPD [61, 100]. The differences in the release of IL- $1 \alpha$ and/or IL- $1 \beta$ in various models need further studies for clarification and may be due the different times of cytokine release [58].

IL-1 signalling in vivo is also involved in airway remodelling and emphysema in COPD. Knock-out of IL-1R1 and IL-1 $\beta$ neutralisation in mice not only protected against emphysema after 6 months of cigarette smoke exposure, but also caused complete protection from cigarette smoke-induced small airway remodelling [30]. Added to this, LAPPALAINEN et al. [9] showed that overexpression of IL-1 $\beta$ in mice lung epithelium leads to a robust inflammatory phenotype accompanied by emphysema and airway 
remodelling. This was mediated through increased production of matrix metalloproteinase (MMP)-9 and -12 , neutrophil chemoattractant $\mathrm{KC}$, and macrophage inflammatory protein-2 [9]. Taken together, these studies indicate that IL- $1 \alpha / \beta$ signalling is implicated in cigarette smoke- and infection-induced chronic inflammation, airway remodelling and emphysema, and either interacts with or affects almost all known mediators and disease processes involved in COPD.

To further highlight the complexity of IL-1 signalling in COPD pathogenesis, multicellular co-culture models have been used to reveal its crucial role in dysregulated cellular communication, leading to aberrant repair processes in the lung. Here, IL-1 signalling has been shown to be the main driver of a disturbed epithelial-fibroblast communication in the lung epithelial-mesenchymal trophic unit (EMTU) in COPD [62]. Through the use of an in vitro co-culture model, we found that cigarette smoke exposure caused COPD-derived airway epithelial cells to produce increased levels of IL-1 $\alpha$ that stimulated lung fibroblasts to release inflammatory mediators, such as CXCL8, while suppressing lung fibroblast ECM expression [62]. Lung fibroblasts are the major cells involved in matrix turnover, and ECM suppression could play a significant role in COPD in terms of both emphysematous tissue destruction and the most recently understood early loss of small airways [101]. Our findings are in line with SuwARA et al. [97], who showed that epithelial damage, either via thapsigargin to simulate endoplasmic reticulum stress or $\mathrm{H}_{2} \mathrm{O}_{2}$ to induce reactive oxidative species, caused an increased release of IL- $1 \alpha$. Furthermore, conditioned medium from damaged bronchial epithelium induced an IL-1 $\alpha$-dependent release of pro-inflammatory mediators CXCL8 and IL-6 from lung fibroblasts [97]. This effect was amplified after stimulation with the viral mimic poly(I:C) [97]. Hill et al. [102] corroborated these findings by showing that poly(I:C) and rhinovirus stimulation caused an epithelial-derived IL-1 $\alpha$-dependent release of CXCL8 and IL-6 from lung fibroblasts in a polarised EMTU model. Since viral infections have been associated with exacerbations in COPD, the involvement of IL-1 signalling in a disturbed cellular cross-talk associated with both cigarette smoke- and viral-induced acute inflammation demonstrates a prominent role for IL-1 in not only stable COPD, but also during exacerbations.

Our co-culture studies also highlighted the role of disturbed epigenetic regulation of the IL-1 pathway in contributing to aberrant epithelial-fibroblast communication in COPD pathogenesis. miR-146a is a known suppressor of IL-1 signalling, which is induced in lung epithelial and mesenchymal cells after IL-1 stimulation, acting as an anti-inflammatory regulator [103-105]. We reported lower induction of miR-146a-5p in COPD-derived lung fibroblasts compared with controls upon co-culture with airway epithelial cells [57]. This miR-146a-5p induction was epithelial IL-1 $\alpha$ dependent and the lower expression in lung fibroblasts from COPD patients was associated with the SNP rs2910164 (GG allele), which caused reduced expression of mature miR-146a-5p [106]. Thus, we proposed that dysregulated epigenetic control of IL-1 in COPD fibroblasts may lead to an exaggerated IL-1-mediated inflammatory response and, as such, contribute to abnormal repair in COPD (figure 3) [57].

These studies show the involvement of IL-1 as a master regulator in the complex interplay of mediators that are dysregulated in COPD disease pathogenesis. In addition, a unique role of IL-1 in aberrant cellular communication and repair in the EMTU may provide an explanation for the molecular mechanisms involved in small airway disease in COPD.

\section{The paradox of IL-1 targeted therapeutics for asthma and COPD}

The studies presented here demonstrate that IL- $1 \alpha$ and IL- $1 \beta$ are clearly involved in the disease pathogenesis of asthma and COPD (figure 4). However, this wealth of data has failed to translate into successful therapeutics for asthma and COPD. Interestingly, IL-1 is not the only mediator that has failed to be translated into successful therapies. Examples of failed therapeutics against important mediators in COPD include anti-IL-5 (benralizumab) [107], anti-IL-17 (CNTO6785) [108], anti-CXCR2 (MK-7123) [109], anti-TNF- $\alpha$ (etanercept) [110], anti-MMP-9/12 (AZD1236) [111] and the neutrophil elastase inhibitor (AZD9668) [112]. In asthma, the anti-IL-13 antibody (tralokinumab, CAT-354) failed across six clinical trials [113] and the humanised anti-IL-4 monoclonal antibody (pascolizumab, SB 240683) also had no therapeutic benefit [114]. Although benralizumab effectively blocks IL-5 for the treatment of severe eosinophilic asthma, this effect is only partial and the disease burden in some patients is unaffected [115]. In addition, administration of the inhaled IL-4/IL-13 antagonist pitrankinra, at different doses (1, 3 or $10 \mathrm{mg}$ given twice daily for 12 weeks), failed in clinical trials comparing the entire asthma patient population to the placebo control [116]. However, the $10 \mathrm{mg}$ dose of pitrankinra significantly attenuated exacerbation rates in the asthma patients with specific SNPs (rs1029489GG and rs8832GG) in the gene encoding the receptor for IL-4 (IL4RA) [116]. This showed that understanding the pharmacogenomics and careful stratification of patient cohorts might be the way forward for clinical trials. This stratification could be informed by studies such as those in Japan [53] and Brazil [91] that found associations between nonatopic asthma and lower serum levels of IL-1RA caused by two alleles in the IL1RN gene and a 


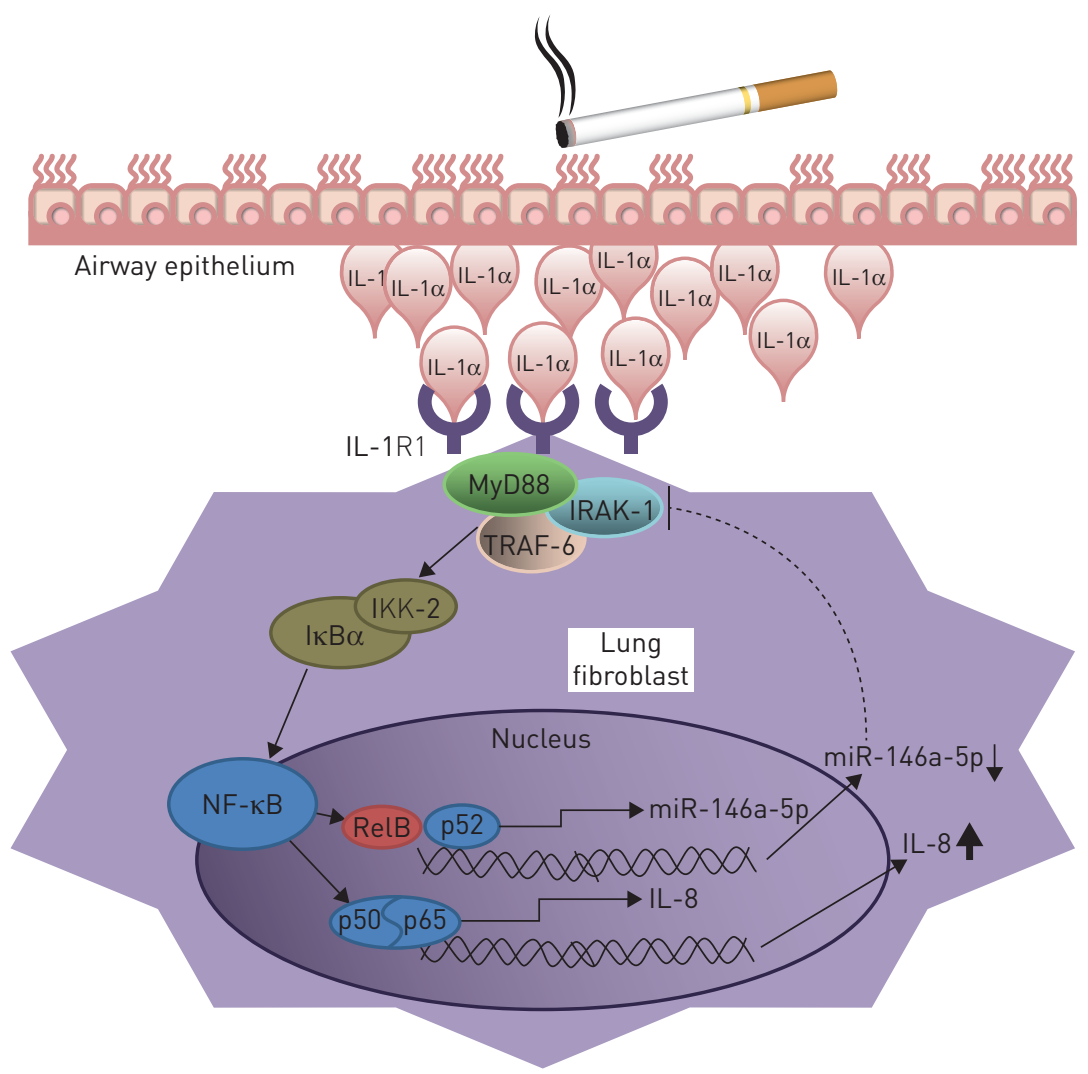

FIGURE 3 Decreased miR-146a-5p induction contributes to increased lung fibroblast-mediated CXCL8 release in chronic obstructive pulmonary disease (COPD). IL: interleukin; MyD88: myeloid differentiation primary response gene 88; IRAK: IL-1 receptor-associated kinase; TRAF: tumour necrosis factor receptor-associated factor. Airway epithelial-derived IL- $1 \alpha$ release after cigarette smoke exposure causes an induction of miR-146a-5p expression in addition to CXCL8 release from lung fibroblasts (solid lines). miR-146a-5p regulates the inflammatory properties of IL-1 by binding to and downregulating the expression of IRAK-1 downstream of the IL-1 pathway in a feedback loop (dotted line) to dampen NF-KB activation and the inflammation. However, the IL-1 $\alpha$-induced increase in miR-146a-5p expression in COPD-derived fibroblasts is lower compared with fibroblasts derived from control individuals. This leads to a dampened feedback inhibition of NF- $\mathrm{KB}$ activation and an exaggerated pro-inflammatory response due to an increased production of airway epithelial-derived IL-1 $\alpha$ from COPD patients. Reproduced from [57] with permission.

gain-of-function SNP in the IL1A gene associating with reduced lung capacity in asthmatic children, respectively. In addition to this, the failure of these therapies could be due to functional redundancies between the major inflammatory mediators involved in both diseases [117]. Again, the failure to translate IL-1 therapies from the laboratory to the bedside may be due to the fact that IL-1 release is triggered by different allergens, noxious and infectious agents in both diseases, and its signalling is involved in and has different roles in most phenotypes of both diseases. Hence, the development of IL-1 therapies may need specific pre-clinical disease models that carefully mimic these specific roles to aid in therapeutic studies. In these pre-clinical models, the interaction between IL-1 and other major mediators such as TGF- $\beta[66,67]$ could also be studied to determine if there might be a net protective role of IL-1 in disease.

Currently, commercially available drugs targeting the IL-1 pathway include anakinra (IL-1RA that binds to IL-1R1), canakinumab (a human monoclonal IgG1 antibody for blocking IL-1 $\beta$ ), rilonacept (a soluble decoy fusion protein that competitively binds to IL-1R) and gevokizumab (a humanised monoclonal anti-IL-1 $\beta$ ) [39]. Of these drugs, significant success has been shown in the use of anakinra in the management of gouty and rheumatoid arthritis as well as cryopyrin-associated periodic syndrome (CAPS), a genetic auto-inflammatory disease [118-120]. The human monoclonal antibody for IL-1 $\beta$ (canakinumab) is also effective for treating most auto-inflammatory disorders including CAPS, TNF receptor-associated periodic syndrome (TRAPS) and familial Mediterranean fever [38, 118]. In the large canakinumab anti-inflammatory thrombosis outcome study (CANTOS) trial, COPD as a confounder was not associated with incident lung cancer cases and drug allocation. Canakinumab was effective at reducing concentrations of IL-6 and high-sensitivity CRP in trial participants, leading to a significant reduction of lung cancers [121]. 


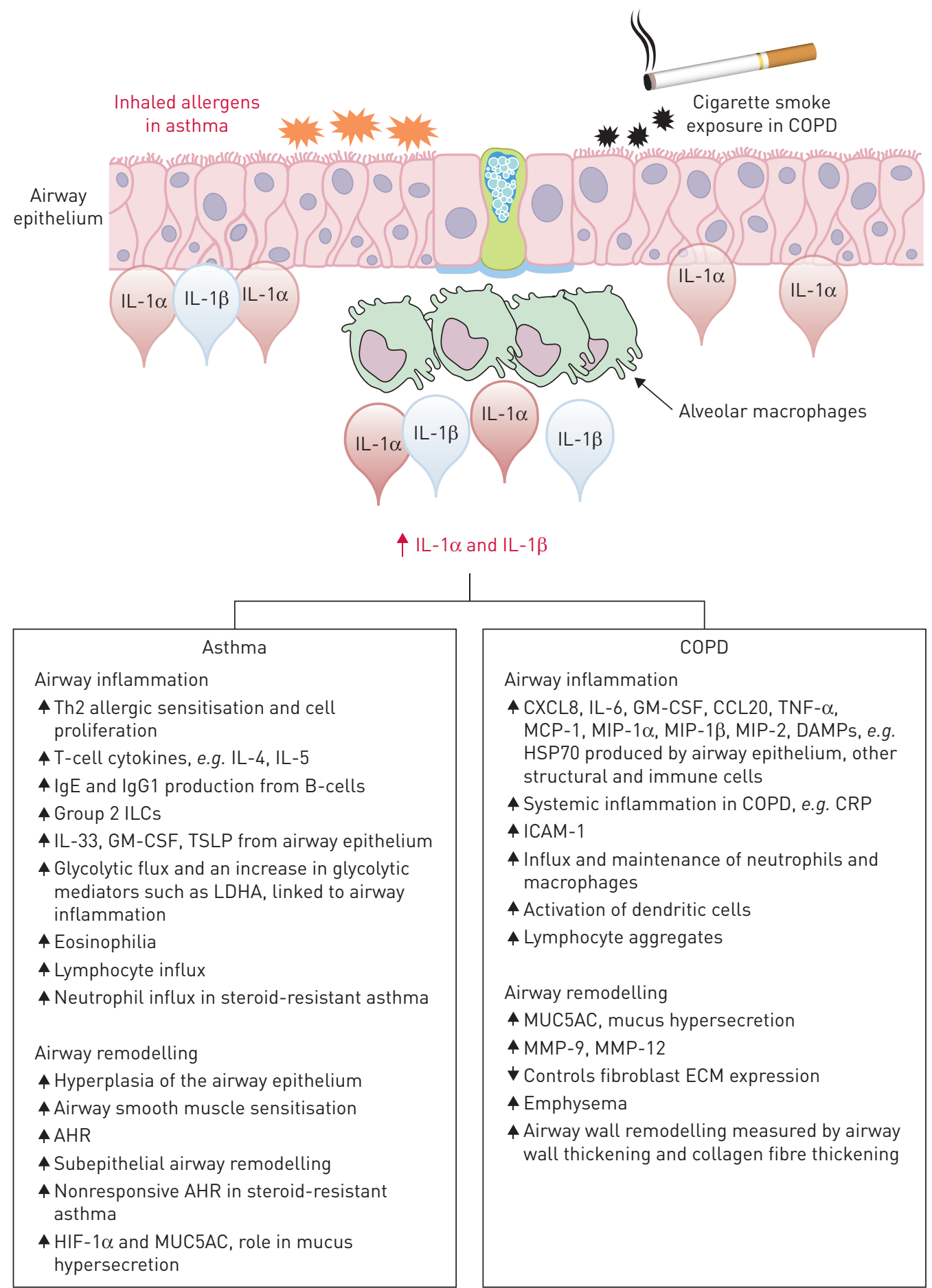

FIGURE 4 Summary of the contributory role of interleukin (IL)-1 signalling in the pathogenesis of asthma and chronic obstructive pulmonary disease (COPD): a schematic representation of the various processes in the pathogenesis of asthma and COPD influenced by IL-1 signalling. Th2: type 2 T-helper cell; ILC: innate lymphoid cell; GM-CSF: granulocyte monocyte-colony stimulating factor; TSLP: thymic stromal lymphopoietin; LDHA: lactate dehydrogenase A; AHR: airway hyperresponsiveness; HIF: hypoxia inducible factor; MUC5AC: mucin 5AC; TNF: tumour necrosis factor; MCP: monocyte chemoattractant protein; MIP: macrophage inflammatory protein; DAMP: damage-associated molecular pattern; HSP: heat shock protein; CRP: C-reactive protein; ICAM: intercellular adhesion molecule; MMP: matrix metalloproteinase; ECM: extracellular matrix. 
The monoclonal anti-IL-1R1 (MEDI8968) has been assessed for different inflammatory diseases including COPD, type 2 diabetes and osteoarthritis [117, 122]. An anti-IL-1 $\alpha$ IgG1 monoclonal antibody (bermekimab, Xilonix) is also currently in various trials (phase 2/3) for diseases including colorectal and lung cancers, type 2 diabetes, acne vulgaris and atopic dermatitis [118]. In addition, evidence supports a role for targeting the inflammasome (responsible for IL-1 $\beta$ production) as a therapeutic strategy in chronic inflammatory diseases such as asthma and COPD. The use of compounds such as the inflammasome inhibiting $\mathrm{P}_{2} \mathrm{X}_{7}$ receptor antagonist (AZD9056) has been investigated in other inflammatory diseases such as rheumatoid arthritis $[39,118]$.

To date, a few clinical trials have looked at the possibility of treating asthma and COPD with IL-1 biologicals (see table 1 for an overview). The problem with some of these trials has been the lack of adequate end-points to aid in assessing the impact of these studies on disease pathogenesis. In addition to adequate end-points, the critical involvement of IL-1 in comorbidities of asthma such as atopic dermatitis as well as hypertension, type 2 diabetes and obesity for both diseases presents a unique cohort of patients in which IL-1 treatments can be assessed $[123,124]$. Again, since IL-1 has been strongly associated with exacerbations in both diseases, clinical trials could be undertaken in specific patients who are prone to a higher rate of exacerbations [37]. This is noteworthy since IL-1 is a prominent cytokine released during infections of the airways, which is a major trigger of exacerbations [29, 86, 99]. Also, since IL-1 is released as one of the main prominent initial mediators in response to various noxious particles, clinical trials could be designed to target early disease in asthma and COPD. In line with this, there are two ongoing clinical trials to assess the effectiveness of anakinra as a rescue treatment for airway inflammation in allergic asthma either through early- or late-phase administration after allergen challenge [125, 126]. With regard to COPD, clinical trials involve patients with moderate to severe disease. However, recent evidence has demonstrated that up to $41 \%$ of the smallest conducting airways are already lost in mild COPD patients [101], indicating that treatment strategies and trials need to be focused on early disease.

In a randomised double-blind placebo-controlled trial presented as a conference abstract, patients with mild asthma were given $10 \mathrm{mg} \cdot \mathrm{kg}^{-1}$ of canakinumab twice, with a 15 -day interval between the first and second dose, and an allergen challenge test was performed on the start date and day 28 [127]. The results of this trial were positive and showed a significant reduction of circulating levels of IL-1 $\beta$ with a reduced rate of late-phase asthma response compared with pre-treatment $[38,127]$. For COPD, a phase $1 / 2$ clinical

TABLE 1 A Summary of clinical trials of interleukin (IL)-1 biologics in asthma and chronic obstructive pulmonary disease (COPD)

Intervention

Disease Phase ClinicalTrials.

Status

Expected outcome

Results

Reference gov identifier

\begin{tabular}{|c|c|c|c|c|c|c|c|}
\hline \multicolumn{8}{|l|}{ Asthma } \\
\hline $\begin{array}{l}\text { Anakinra (rhIL-1RA: } \\
\text { late-phase } \\
\text { administration) }\end{array}$ & $\begin{array}{l}\text { Allergic } \\
\text { asthma }\end{array}$ & 1 and 2 & NCT03513458 & Ongoing & $\begin{array}{l}\text { Examine anakinra } \\
\text { effectiveness to rescue } \\
\text { allergic inflammation }\end{array}$ & NA & [125] \\
\hline ACZ885 (canakinumab) & LAR & NA & NA & Completed & NA & $\begin{array}{l}\text { Safe, well tolerated and } \\
\text { lowered LAR by } 28 \%\end{array}$ & [127] \\
\hline $\begin{array}{l}\text { MEDI8968 (IL-1R1 } \\
\text { monoclonal antibody) }\end{array}$ & COPD & 2 & NCT01448850 & Completed & NA & $\begin{array}{l}\text { Failed to reach primary } \\
\text { end-point of reducing } \\
\text { moderate and acute } \\
\text { exacerbation rate }\end{array}$ & [117] \\
\hline ACZ885 (canakinumab) & COPD & 1 and 2 & NCT00581945 & Completed & NA & $\begin{array}{l}\text { Statistical analysis not } \\
\text { provided }\end{array}$ & [128] \\
\hline
\end{tabular}

rh: recombinant human; IL-1RA: IL-1 receptor antagonist; LAR: late asthmatic response; IL-1R1: IL-1 receptor 1; NA: not applicable. 
trial assessed the pharmacokinetic properties of canakinumab, but findings were inconclusive as statistical data related to the trial were not provided [128]. It was also reported that administration of $400 \mathrm{mg}$ of the $\mathrm{P}_{2} \mathrm{X}_{7}$ antagonist, AZD9056, once a day for 4 weeks did not change lung function in moderate to severe COPD patients [129]. However, there were no further details in this report. A double-blind placebo-controlled trial of the humanised monoclonal IL-1R1 antibody (MEDI8968) in COPD patients failed to reach its primary end-point of reducing the rates of moderate and acute exacerbations [117]. In this trial, the projected annual rate of moderate to severe AECOPD of 1.27 in the placebo group estimated in the initial power calculation was higher than the actual observed rate of 0.78 . Hence, although there was a $32 \%$ reduction in exacerbation rate, this fell short of the $40 \%$ reduction in exacerbations needed to reach statistical significance. Moreover, although administration of MEDI8968 consistently reduced blood neutrophil counts in addition to CRP and fibrinogen levels in COPD patients compared with controls, clinical surrogate markers were used to assess levels of circulating IL-1 [117]. Again, pulmonary levels of the administered drug were not assessed. Although this does not prove that the lung was under-dosed, it also cannot be concluded that the lung was properly dosed. Future, larger and adequately powered trials that assess the pulmonary effects of IL-1 therapeutics are therefore needed to provide a clearer picture of the role of IL-1 therapeutics in the treatment of COPD.

Future trials and studies to target IL-1 inhibition should consider that although both IL-1 $\alpha$ and IL-1 $\beta$ are involved in asthma and COPD pathogenesis, the roles of these two cytokines may be different under particular disease triggers. As an example, mouse studies in both asthma and COPD have shown early IL- $1 \alpha$ release independent of IL- $1 \beta$ could be a key initiator of disease pathogenesis. However, currently available commercial biologicals do not specifically target IL- $1 \alpha$, although the anti-IL-1 $\alpha$ IgG1 monoclonal antibody (bermekimab) is currently in various trials (phase $2 / 3$ ) for other diseases. Thus, current studies or trials that are directed towards also targeting the activity of IL- $1 \alpha$, and not only IL-1 $\beta$, may provide more promising therapeutic potential in both COPD and asthma. As IL-1 strongly associates with increased neutrophilia in both diseases and is associated with disease exacerbations [37], this may serve as an example of a specific disease phenotype in which IL-1 together with other master cytokines could be biomarkers for responder populations and biologicals could be further investigated.

As with the blockade of various other master regulatory cytokines, blocking the IL-1 pathway in chronic diseases such as asthma and COPD raises concerns about off-target effects that may occur due to IL-1's important role in normal immune functions of the body. As seen in most cytokine therapies, the number of occurrences of routine bacterial infections have been reported to be increased with IL-1 blockade [118]. However, compared with other anti-cytokine therapies such as anti-TNF treatment for inflammatory diseases, there is virtually a complete lack of opportunistic infection following anti-IL-1 therapy [118]. In line with this, anakinra is remarkably safe in chronic inflammatory diseases such as arthritis, where patients have been on daily doses for over 10 years $[130,131]$. Thus, clinical trials for anti-IL-1 therapy in asthma and COPD need to be carefully planned with the right dosing and targeting of proper disease phenotypes to minimise any off-target effects on the normal immune defence within the lung.

\section{Conclusions}

In this review, we have demonstrated clear evidence for a role of IL- $1 \alpha$ and IL- $1 \beta$ in the disease pathogenesis of asthma and COPD. However, a major unanswered question is: how do these two closely related cytokines that bind to the same receptor and activate the same pathway drive divergent inflammatory processes in asthma and COPD? Further studies are needed to determine how different environmental triggers can stimulate differential IL- $1 \alpha / \beta$ signalling in asthma and COPD. Although a few trials have reported varying data targeting the function and activity of both IL- $1 \alpha$ and IL-1 $\beta$, there is the need for better stratification and targeting of specific disease cohorts in future trials. The use of specific antibodies against IL- $1 \alpha$ and IL-1 $\beta$ and lung-specific biomarkers may also be worth examining in future trials to determine if targeting these cytokines is a promising therapeutic approach for asthma and COPD patients.

Conflict of interest: E.T. Osei has nothing to disclose. C-A. Brandsma has nothing to disclose. W. Timens reports institutional fees for consultancy from Pfizer, institutional fees for lectures from GSK, Chiesi, Lilly Oncology and Boehringer Ingelheim, travel costs and institutional fees for lectures and consultancy from Roche Diagnostics/Ventana, grants from Dutch Asthma Fund, travel costs from Biotest, institutional fees for consultancy and conducting courses from MSD, AstraZeneca and Bristol-Myers Squibb, institutional fees for lectures and consultancy from Novartis, outside the submitted work. I.H. Heijink has nothing to disclose. T-L. Hackett has nothing to disclose.

\section{References}

1 Adeloye D, Chua S, Lee C, et al. Global and regional estimates of COPD prevalence: systematic review and meta-analysis. J Glob Health 2015; 5: 020415. 

Study): a population-based prevalence study. Lancet 2007; 370: 741-750. org/2019-gina-report-global-strategy-for-asthma-management-and-prevention Date last accessed: March 10, 2019. Barnes PJ. Immunology of asthma and chronic obstructive pulmonary disease. Nat Rev Immunol 2008; 8 ; 183-192.

Postma DS, Timens W. Remodeling in asthma and chronic obstructive pulmonary disease. Proc Am Thorac Soc 2006; 3: 434-439.

$6 \quad$ Chung KF. Cytokines in chronic obstructive pulmonary disease. Eur Respir J 2001; 34: Suppl. 50s-59s.

7 Pauwels NS, Bracke KR, Dupont LL, et al. Role of IL-1alpha and the Nlrp3/caspase-1/IL-1beta axis in cigarette smoke-induced pulmonary inflammation and COPD. Eur Respir J 2011; 38: 1019-1028.

8 Botelho MF, Bauer CMT, Finch D, et al. IL-1 alpha/ IL1-R1 expression in chronic obstructive pulmonary disease and mechanistic relevance to smoke-induced neutrophilia in mice. PLoS One 2011; 6: e28457-e28457.

9 Lappalainen U, Whitsett JA, Wert SE, et al. Interleukin-1beta causes pulmonary inflammation, emphysema, and airway remodeling in the adult murine lung. Am J Respir Cell Mol Biol 2005; 32: 311-318.

10 Ekberg-Jansson A, Andersson B, Bake B, et al. Neutrophil-associated activation markers in healthy smokers relates to a fall in $\mathrm{DL}_{\mathrm{CO}}$ and to emphysematous changes on high resolution CT. Respir Med 2001; 95: 363-373.

11 Sousa AR, Lane SJ, Nakhosteen JA, et al. Expression of interleukin-1 beta (IL-1beta) and interleukin-1 receptor antagonist (IL-1ra) on asthmatic bronchial epithelium. Am J Respir Crit Care Med 1996; 154: 1061-1066.

12 Willart MA, Deswarte K, Pouliot $\mathrm{P}$, et al. Interleukin-1 $\alpha$ controls allergic sensitization to inhaled house dust mite via the epithelial release of GM-CSF and IL-33. J Exp Med 2012; 209: 1505-1517.

13 Schmitz N, Kurrer M, Kopf M. The IL-1 receptor 1 is critical for Th2 cell type airway immune responses in a mild but not in a more severe asthma model. Eur J Immunol 2003; 33: 991-1000.

14 Takhar P, Corrigan CJ, Smurthwaite L, et al. Class switch recombination to IgE in the bronchial mucosa of atopic and nonatopic patients with asthma. J Allergy Clin Immunol 2007; 119: 213-218.

15 Barnes PJ. The cytokine network in asthma and chronic obstructive pulmonary disease. J Clin Invest 2008; 118: 3546-3556.

16 Chung KF. Asthma phenotyping: a necessity for improved therapeutic precision and new targeted therapies. J Intern Med 2016; 279: 192-204.

17 Chung KF, Barnes PJ. Cytokines in asthma. Thorax 1999; 54: 825-857.

18 Laniado-Laborín R. Smoking and chronic obstructive pulmonary disease (COPD). Parallel epidemics of the 21 century. Int J Environ Res Public Health 2009; 6: 209-224.

19 Demedts IK, Bracke KR, Van Pottelberge G, et al. Accumulation of dendritic cells and increased CCL20 levels in the airways of patients with chronic obstructive pulmonary disease. Am J Respir Crit Care Med 2007; 175: 998-1005.

20 Demedts IK, Joos GF, Brusselle GG. Pulmonary dendritic cells: playing ball in the BAL? Eur Respir J 2007; 30: $823-824$.

21 Opitz B, van Laak V, Eitel J, et al. Innate immune recognition in infectious and noninfectious diseases of the lung. Am J Respir Crit Care Med 2010; 181: 1294-1309.

22 Pouwels SD, Heijink $\mathrm{IH}$, ten Hacken $\mathrm{NH}$, et al. DAMPs activating innate and adaptive immune responses in COPD. Mucosal Immunol 2014; 7: 215-226.

23 Rahman I. Antioxidant therapies in COPD. Int I Chron Obstruct Pulmon Dis 2006; 1: 15-29.

24 Decramer M, Janssens W, Miravitlles M. Chronic obstructive pulmonary disease. Lancet 2012; 379: 1341-1351.

25 Hogg JC, Timens W. The pathology of chronic obstructive pulmonary disease. Annu Rev Pathol 2009; 4: 435-459.

26 Whelan R, Kim C, Chen M, et al. Role and regulation of interleukin-1 molecules in pro-asthmatic sensitised airway smooth muscle. Eur Respir J 2004; 24: 559-567.

27 McKay S, Sharma HS. Autocrine regulation of asthmatic airway inflammation: role of airway smooth muscle. Respir Res 2002; 3: 11.

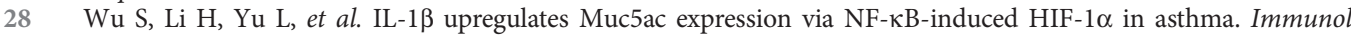
Lett 2017; 192: 20-26.

29 Bucher H, Mang S, Keck M, et al. Neutralization of both IL- $1 \alpha / \mathrm{IL}-1 \beta$ plays a major role in suppressing combined cigarette smoke/virus-induced pulmonary inflammation in mice. Pulm Pharmacol Ther 2017; 44: 96-105.

30 Churg A, Zhou S, Wang X, et al. The role of interleukin-1beta in murine cigarette smoke-induced emphysema and small airway remodeling. Am J Respir Cell Mol Biol 2009; 40: 482-490.

31 Chan V, Burgess JK, Ratoff JC, et al. Extracellular matrix regulates enhanced eotaxin expression in asthmatic airway smooth muscle cells. Am J Respir Crit Care Med 2006; 174: 379-385.

32 Postma DS, Reddel HK, ten Hacken NH, et al. Asthma and chronic obstructive pulmonary disease: similarities and differences. Clin Chest Med 2014; 35: 143-156.

33 Zou Y, Chen X, Liu J, et al. Serum IL-1 $\beta$ and IL-17 levels in patients with COPD: associations with clinica parameters. Int J Chron Obstruct Pulmon Dis 2017; 12: 1247-1254.

34 Kim V, Han MK, Vance GB, et al. The chronic bronchitic phenotype of COPD: an analysis of the COPDGene Study. Chest 2011; 140: 626-633.

35 Boschetto P, Miniati M, Miotto D, et al. Predominant emphysema phenotype in chronic obstructive pulmonary. Eur Respir J 2003; 21: 450-454.

36 Postma DS, Rabe KF. The asthma-COPD overlap syndrome. N Engl J Med 2015; 373: 1241-1249.

37 Baines KJ, Fu JJ, McDonald VM, et al. Airway gene expression of IL-1 pathway mediators predicts exacerbation risk in obstructive airway disease. Int J Chron Obstruct Pulmon Dis 2017; 12: 541-550.

38 Rogliani P, Calzetta L, Ora J, et al. Canakinumab for the treatment of chronic obstructive pulmonary disease. Pulm Pharmacol Ther 2015; 31: 15-27.

39 Borthwick LA. The IL-1 cytokine family and its role in inflammation and fibrosis in the lung. Semin Immunopathol 2016; 38: 517-534. 
Garlanda C, Dinarello CA, Mantovani A. The interleukin-1 family: back to the future. Immunity 2013; 39: 1003-1018.

Garofalo R, Mei F, Espejo R, et al. Respiratory syncytial virus infection of human respiratory epithelial cells up-regulates class I MHC expression through the induction of IFN-beta and IL-1 alpha. J Immunol 1996; 157: 2506-2513.

Arend WP. The balance between IL-1 and IL-1Ra in disease. Cytokine Growth Factor Rev 2002; 13: 323-340.

Gicquel T, Robert S, Loyer P, et al. IL-1 $\beta$ production is dependent on the activation of purinergic receptors and NLRP3 pathway in human macrophages. FASEB J 2015; 29: 4162-4173.

Gasse P, Mary C, Guenon I, et al. IL-1R1/MyD88 signaling and the inflammasome are essential in pulmonary inflammation and fibrosis in mice. J Clin Invest 2007; 117: 3786-3799.

Gasse P, Riteau N, Charron S, et al. Uric acid is a danger signal activating NALP3 inflammasome in lung injury inflammation and fibrosis. Am J Respir Crit Care Med 2009; 179: 903-913.

Michaudel C, Couturier-Maillard A, Chenuet P, et al. Inflammasome, IL-1 and inflammation in ozone-induced lung injury. Am J Clin Exp Immunol 2016; 5: 33-40.

Li X, Commane M, Jiang Z, et al. IL-1-induced NFkappa B and c-Jun N-terminal kinase (JNK) activation diverge at IL-1 receptor-associated kinase (IRAK). Proc Natl Acad Sci USA 2001; 98: 4461-4465.

Huang J, Gao X, Li S, et al. Recruitment of IRAK to the interleukin 1 receptor complex requires interleukin 1 receptor accessory protein. Proc Natl Acad Sci USA 1997; 94: 12829-12832.

Dinarello CA. The IL-1 family and inflammatory diseases. Clin Exp Rheumatol 2002; 20: 5 Suppl. 27, S1-13.

Rickard JA, O'Donnell JA, Evans JM, et al. RIPK1 regulates RIPK3-MLKL-driven systemic inflammation and emergency hematopoiesis. Cell 2014; 157: 1175-1188.

Colotta F, Re F, Muzio M, et al. Interleukin-1 type II receptor: a decoy target for IL-1 that is regulated by IL-4. Science 1993; 261: 472-475.

Gagné-Ouellet V, Guay SP, Boucher-Lafleur AM, et al. DNA methylation signature of interleukin 1 receptor type II in asthma. Clin Epigenetics 2015; 7: 80.

Mao XQ, Kawai M, Yamashita T, et al. Imbalance production between interleukin-1beta (IL-1beta) and IL-1 receptor antagonist (IL-1Ra) in bronchial asthma. Biochem Biophys Res Commun 2000; 276: 607-612.

Sapey E, Ahmad A, Bayley D, et al. Imbalances between interleukin-1 and tumor necrosis factor agonists and antagonists in stable COPD. J Clin Immunol 2009; 29: 508-516.

Santini P, Politi L, Vedova PD, et al. The inflammatory circuitry of miR-149 as a pathological mechanism in osteoarthritis. Rheumatol Int 2014; 34: 711-716.

Jiang W, Kong L, Ni Q, et al. miR-146a ameliorates liver ischemia/reperfusion injury by suppressing IRAK1 and TRAF6. PLoS One 2014; 9: e101530.

Osei ET, Florez-Sampedro L, Tasena H, et al. miR-146a-5p plays an essential role in the aberrant epithelialfibroblast cross-talk in COPD. Eur Respir J 2017; 49: 1602538.

Rabolli V, Badissi AA, Devosse R, et al. The alarmin IL-1 $\alpha$ is a master cytokine in acute lung inflammation induced by silica micro- and nanoparticles. Part Fibre Toxicol 2014; 11: 69.

Yazdi AS, Guarda G, Riteau N, et al. Nanoparticles activate the NLR pyrin domain containing 3 (Nlrp3) inflammasome and cause pulmonary inflammation through release of IL-1 $\alpha$ and IL-1 $\beta$. Proc Natl Acad Sci USA 2010; 107: 19449-19454.

Michaudel C, Maillet I, Fauconnier L, et al. Interleukin-1 $\alpha$ mediates ozone-induced myeloid differentiation factor-88-dependent epithelial tissue injury and inflammation. Front Immunol 2018; 9: 916.

Hirota JA, Marchant DJ, Singhera GK, et al. Urban particulate matter increases human airway epithelial cell IL-1 $\beta$ secretion following scratch wounding and H1N1 influenza A exposure in vitro. Exp Lung Res 2015; 41: 353-362.

Osei ET, Noordhoek JA, Hackett TL, et al. Interleukin-1 $\alpha$ drives the dysfunctional cross-talk of the airway epithelium and lung fibroblasts in COPD. Eur Respir J 2016; 48: 359-369.

Neyt K, GeurtsvanKessel CH, Deswarte K, et al. Early IL-1 signaling promotes iBALT induction after influenza virus infection. Front Immunol 2016; 7: 312

Martin TR, Frevert CW. Innate immunity in the lungs. Proc Am Thorac Soc 2005; 2: 403-411.

Strieter RM, Belperio JA, Keane MP. Cytokines in innate host defense in the lung. J Clin Invest 2002; 109: 699-705.

Zhang HY, Phan SH. Inhibition of myofibroblast apoptosis by transforming growth factor beta ${ }_{1}$. Am J Respir Cell Mol Biol 1999; 21: 658-665.

Mia MM, Boersema M, Bank RA. Interleukin-1beta attenuates myofibroblast formation and extracellular matrix

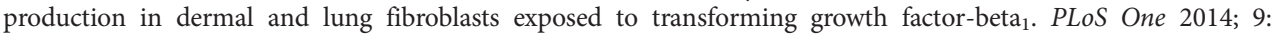
e91559.

8 White KE, Ding Q, Moore BB, et al. Prostaglandin $\mathrm{E}_{2}$ mediates IL-1beta-related fibroblast mitogenic effects in acute lung injury through differential utilization of prostanoid receptors. J Immunol 2008; 180: 637-646.

Lee JH, Wang LC, Yu HH, et al. Type I IL-1 receptor (IL-1RI) as potential new therapeutic target for bronchial asthma. Mediators Inflamm 2010; 2010: 567351.

Broide DH, Lotz M, Cuomo AJ, et al. Cytokines in symptomatic asthma airways. J Allergy Clin Immunol 1992; 89: 958-967.

Thomas SS, Chhabra SK. A study on the serum levels of interleukin-1beta in bronchial asthma. J Indian Med Assoc 2003; 101: 282

Konno S, Gonokami Y, Kurokawa M, et al. Cytokine concentrations in sputum of asthmatic patients. Int Arch Allergy Immunol 1996; 109: 73-78. J Allergy Clin Immunol 2017; 139: 1808-1818.

Liu W, Liu S, Verma M, et al. Mechanism of $\mathrm{T}_{\mathrm{H}} 2 / \mathrm{T}_{\mathrm{H}} 17$-predominant and neutrophilic $\mathrm{T}_{\mathrm{H}} 2 / \mathrm{T}_{\mathrm{H}} 17$-low subtypes of asthma. J Allergy Clin Immunol 2017; 139: 1548-1558.

Sundaram K, Mitra S, Gavrilin MA, et al. House dust mite allergens and the induction of monocyte interleukin $1 \beta$ production that triggers an IкB $\zeta$-dependent granulocyte macrophage colony-stimulating factor release from human lung epithelial cells. Am J Respir Cell Mol Biol 2015; 53: 400-411. 
de Vries M, Hesse L, Jonker MR, et al. Pim1 kinase activity preserves airway epithelial integrity upon house dust mite exposure. Am J Physiol Lung Cell Mol Physiol 2015; 309: L1344-L1353.

Nakae S, Komiyama Y, Yokoyama $\mathrm{H}$, et al. IL-1 is required for allergen-specific $\mathrm{T}_{\mathrm{h}} 2$ cell activation and the development of airway hypersensitivity response. Int Immunol 2003; 15: 483-490.

Johnson VJ, Yucesoy B, Luster MI. Prevention of IL-1 signaling attenuates airway hyperresponsiveness and inflammation in a murine model of toluene diisocyanate-induced asthma. J Allergy Clin Immunol 2005; 116: 851-858.

Cavagnero K, Doherty TA. Cytokine and lipid mediator regulation of group 2 innate lymphoid cells (ILC2s) in human allergic airway disease. J Cytokine Biol 2017; 2: 116.

Ohne Y, Silver JS, Thompson-Snipes L, et al. IL-1 is a critical regulator of group 2 innate lymphoid cell function and plasticity. Nat Immunol 2016; 17: 646-655.

Qian X, Aboushousha R, van de Wetering C, et al. IL-1/inhibitory $\mathrm{\kappa B}$ kinase $\varepsilon$-induced glycolysis augment epithelial effector function and promote allergic airways disease. J Allergy Clin Immunol 2017; 142: 435-450

Besnard AG, Togbe D, Couillin I, et al. Inflammasome-IL-1-Th17 response in allergic lung inflammation. J Mol Cell Biol 2012; 4: 3-10.

Madouri F, Guillou N, Fauconnier L, et al. Caspase-1 activation by NLRP3 inflammasome dampens IL-33-dependent house dust mite-induced allergic lung inflammation. J Mol Cell Biol 2015; 7: 351-365.

Besnard AG, Guillou N, Tschopp J, et al. NLRP3 inflammasome is required in murine asthma in the absence of aluminum adjuvant. Allergy 2011; 66: 1047-1057.

Idzko M, Hammad $\mathrm{H}$, van Nimwegen $\mathrm{M}$, et al. Extracellular ATP triggers and maintains asthmatic airway inflammation by activating dendritic cells. Nat Med 2007; 13: 913-919.

Kim RY, Pinkerton JW, Essilfie AT, et al. Role for NLRP3 inflammasome-mediated, IL-1 $\beta$-dependent responses in severe, steroid-resistant asthma. Am J Respir Crit Care Med 2017; 196: 283-297.

Seys SF, Lokwani R, Simpson JL, et al. New insights in neutrophilic asthma. Curr Opin Pulm Med 2019; 25: 113-120.

Simpson JL, Phipps S, Baines KJ, et al. Elevated expression of the NLRP3 inflammasome in neutrophilic asthma. Eur Respir J 2014; 43: 1067-1076.

Evans MD, Esnault S, Denlinger LC, et al. Sputum cell IL-1 receptor expression level is a marker of airway neutrophilia and airflow obstruction in asthmatic patients. J Allergy Clin Immunol 2018; 142: 415-423.

Osei ET, Mostaco-Guidolin L, Warner S, et al. The role of interleukin-1 in driving inflammation and remodeling in the asthmatic EMTU. Am J Respir Crit Care Med 2017; 195: A7248.

Leal VNC, Genov IR, Mallozi MC, et al. Polymorphisms in inflammasome genes and risk of asthma in Brazilian children. Mol Immunol 2018; 93: 64-67.

Singh S, Verma SK, Kumar S, et al. Correlation of severity of chronic obstructive pulmonary disease with potential biomarkers. Immunol Lett 2018; 196: 1-10.

Colarusso C, Terlizzi M, Molino A, et al. Role of the inflammasome in chronic obstructive pulmonary disease (COPD). Oncotarget 2017; 8: 81813-81824.

Wang H, Lv C, Wang S, et al. NLRP3 inflammasome involves in the acute exacerbation of patients with chronic obstructive pulmonary disease. Inflammation 2018; 41: 1321-1333.

Culpitt SV, Rogers DF, Shah P, et al. Impaired inhibition by dexamethasone of cytokine release by alveolar macrophages from patients with chronic obstructive pulmonary disease. Am J Respir Crit Care Med 2003; 167: $24-31$.

Uh ST, Koo SM, Kim Y, et al. The activation of NLRP3-inflammsome by stimulation of diesel exhaust particles in lung tissues from emphysema model and RAW 264.7 cell line. Korean J Intern Med 2017; 32: 865-874.

Suwara MI, Green NJ, Borthwick LA, et al. IL-1alpha released from damaged epithelial cells is sufficient and essential to trigger inflammatory responses in human lung fibroblasts. Mucosal Immunol 2014; 7: 684-693.

Doz E, Noulin N, Boichot E, et al. Cigarette smoke-induced pulmonary inflammation is TLR4/MyD88 and IL-1R1/MyD88 signaling dependent. J Immunol 2008; 180: 1169-1178.

Nikota JK, Shen P, Morissette MC, et al. Cigarette smoke primes the pulmonary environment to IL-1 $\alpha$ / CXCR-2-dependent nontypeable Haemophilus influenzae-exacerbated neutrophilia in mice. J Immunol 2014; 193: 3134-3145.

Yang W, Ni H, Wang H, et al. NLRP3 inflammasome is essential for the development of chronic obstructive pulmonary disease. Int J Clin Exp Pathol 2015; 8: 13209-13216.

Koo HK, Vasilescu DM, Booth S, et al. Small airways disease in mild and moderate chronic obstructive pulmonary disease: a cross-sectional study. Lancet Respir Med 2018; 6: 591-602.

Hill AR, Donaldson JE, Blume C, et al. IL-1 $\alpha$ mediates cellular cross-talk in the airway epithelial mesenchymal trophic unit. Tissue Barriers 2016; 4: e1206378.

Perry MM, Williams AE, Tsitsiou E, et al. Divergent intracellular pathways regulate interleukin-1beta-induced miR-146a and miR-146b expression and chemokine release in human alveolar epithelial cells. FEBS Lett 2009; 583: 3349-3355.

4 Perry MM, Moschos SA, Williams AE, et al. Rapid changes in microRNA-146a expression negatively regulate the IL-1beta-induced inflammatory response in human lung alveolar epithelial cells. J Immunol 2008; 180: 5689-5698.

Larner-Svensson HM, Williams AE, Tsitsiou E, et al. Pharmacological studies of the mechanism and function of interleukin-1beta-induced miRNA-146a expression in primary human airway smooth muscle. Respir Res 2010; 11: 68.

Jazdzewski K, Murray EL, Franssila K, et al. Common SNP in pre-miR-146a decreases mature miR expression and predisposes to papillary thyroid carcinoma. Proc Natl Acad Sci USA 2008; 105: 7269-7274.

Criner GJ, Celli BR, Brightling CE, et al. Benralizumab for the prevention of COPD exacerbations. N Engl J Med 2019; 381: 1023-1034.

Eich A, Urban V, Jutel M, et al. A randomized, placebo-controlled phase 2 trial of CNTO 6785 in chronic obstructive pulmonary disease. COPD 2017; 14: 476-483.

chronic obstructive pulmonary disease. Am J Respir Crit Care Med 2015; 191: 1001-1011. 
110 Aaron SD, Vandemheen KL, Maltais F, et al. TNF $\alpha$ antagonists for acute exacerbations of COPD: a randomised double-blind controlled trial. Thorax 2013; 68: 142-148.

111 Magnussen H, Watz H, Kirsten A, et al. Safety and tolerability of an oral MMP-9 and -12 inhibitor, AZD1236, in patients with moderate-to-severe COPD: a randomised controlled 6-week trial. Pulm Pharmacol Ther 2011; 24: 563-570.

112 Kuna P, Jenkins M, O’Brien CD, et al. AZD9668, a neutrophil elastase inhibitor, plus ongoing budesonide/ formoterol in patients with COPD. Respir Med 2012; 106: 531-539.

113 Zhang Y, Cheng J, Li Y, et al. The safety and efficacy of anti-IL-13 treatment with tralokinumab (CAT-354) in moderate to severe asthma: a systematic review and meta-analysis. J Allergy Clin Immunol Pract 2019; 7: 2661-2671.

114 Bagnasco D, Ferrando M, Varricchi G, et al. A critical evaluation of anti-IL-13 and anti-IL-4 strategies in severe asthma. Int Arch Allergy Immunol 2016; 170: 122-131.

115 FitzGerald JM, Bleecker ER, Nair P, et al. Benralizumab, an anti-interleukin-5 receptor $\alpha$ monoclonal antibody, as add-on treatment for patients with severe, uncontrolled, eosinophilic asthma (CALIMA): a randomised, double-blind, placebo-controlled phase 3 trial. Lancet 2016; 388: 2128-2141.

116 Slager RE, Otulana BA, Hawkins GA, et al. IL-4 receptor polymorphisms predict reduction in asthma exacerbations during response to an anti-IL-4 receptor $\alpha$ antagonist. J Allergy Clin Immunol 2012; 130: 516-522.

117 Calverley PMA, Sethi S, Dawson M, et al. A randomised, placebo-controlled trial of anti-interleukin-1 receptor 1 monoclonal antibody MEDI8968 in chronic obstructive pulmonary disease. Respir Res 2017; 18: 153.

118 Dinarello CA, Simon A, van der Meer JW. Treating inflammation by blocking interleukin-1 in a broad spectrum of diseases. Nat Rev Drug Discov 2012; 11: 633-652.

119 Ottaviani S, Brunier L, Sibilia J, et al. Efficacy of anakinra in calcium pyrophosphate crystal-induced arthritis: a report of 16 cases and review of the literature. Joint Bone Spine 2013; 80: 178-182.

120 Ottaviani S, Moltó A, Ea HK, et al. Efficacy of anakinra in gouty arthritis: a retrospective study of 40 cases. Arthritis Res Ther 2013; 15: R123.

121 Ridker PM, MacFadyen JG, Thuren T, et al. Effect of interleukin-1 $\beta$ inhibition with canakinumab on incident lung cancer in patients with atherosclerosis: exploratory results from a randomised, double-blind, placebo-controlled trial. Lancet 2017; 390: 1833-1842.

122 Cohen SB, Proudman S, Kivitz AJ, et al. A randomized, double-blind study of AMG 108 (a fully human monoclonal antibody to IL-1R1) in patients with osteoarthritis of the knee. Arthritis Res Ther 2011; 13: R125.

123 Chatila WM, Thomashow BM, Minai OA, et al. Comorbidities in chronic obstructive pulmonary disease. Proc Am Thorac Soc 2008; 5: 549-555.

124 Kankaanranta H, Kauppi P, Tuomisto LE, et al. Emerging comorbidities in adult asthma: risks, clinical associations, and mechanisms. Mediators Inflamm 2016; 2016: 3690628.

125 University of North Carolina Chapel Hill. Late phase administration anakinra as a rescue treatment for inhaled allergen challenge-induced airway inflammation (LateAna). 2018. https://clinicaltrials.gov/ct2/show/ NCT03513458 Date last updated: February 1, 2019. Date last accessed: March 10, 2019.

126 University of North Carolina Chapel Hill. Early phase administration of anakinra as a rescue treatment for inhaled allergen challenge-induced airway inflammation (EarlyAna). 2018. https://clinicaltrials.gov/ct2/show/ NCT03513471 Date last updated: January 31, 2019. Date last accessed: March 10, 2019.

127 Pascoe S, Kanniess F, Bonner J, et al. A monoclonal antibody to IL-1beta attenuates the late asthmatic response to antigen challenge in patients with mild asthma. Eur Respir J 2006; 28: Suppl. 50, 752.

128 Novartis. Safety and efficacy of multiple doses of canakinumab (ACZ885) in chronic obstructive pulmonary disease (COPD) patients. 2007. https://clinicaltrials.gov/ct2/show/NCT00581945 Date last updated: June 30, 2011. Date last accessed: March 10, 2019.

129 AstraZeneca. AZD9056. 2019. https://ncats.nih.gov/files/AZD9056.pdf Date last accessed: March 10, 2019.

130 Mertens M, Singh JA. Anakinra for rheumatoid arthritis: a systematic review. J Rheumatol 2009; 36: 1118-1125.

131 Fleischmann RM. Comparison of the efficacy of biologic therapy for rheumatoid arthritis: can the clinical trials be accurately compared? Rheum Dis Clin North Am 2006; 32: Suppl. 1, 21-28. 